\title{
Affective Modulation of Cognitive Control is Determined by Performance-Contingency and Mediated by Ventromedial Prefrontal and Cingulate Cortex
}

\author{
Senne Braem, ${ }^{1}$ Joseph A. King, ${ }^{2}$ Franziska M. Korb, ${ }^{2}$ Ruth M. Krebs, ${ }^{1}$ Wim Notebaert, ${ }^{1}$ and Tobias Egner ${ }^{2}$ \\ ${ }^{1}$ Department of Experimental Psychology, Ghent University, Ghent, 9000 , Belgium, and ${ }^{2}$ Center for Cognitive Neuroscience, Duke University, Durham, \\ North Carolina 27708
}

\begin{abstract}
Cognitive control requires a fine balance between stability, the protection of an on-going task-set, and flexibility, the ability to update a task-set in line with changing contingencies. It is thought that emotional processing modulates this balance, but results have been equivocal regarding the direction of this modulation. Here, we tested the hypothesis that a crucial determinant of this modulation is whether affective stimuli represent performance-contingent or task-irrelevant signals. Combining functional magnetic resonance imaging with a conflict task-switching paradigm, we contrasted the effects of presenting negative- and positive-valence pictures on the stability/flexibility trade-off in humans, depending on whether picture presentation was contingent on behavioral performance. Both the behavioral and neural expressions of cognitive control were modulated by stimulus valence and performance contingency: in the performance-contingent condition, cognitive flexibility was enhanced following positive pictures, whereas in the nonperformancecontingent condition, positive stimuli promoted cognitive stability. The imaging data showed that, as anticipated, the stability/flexibility trade-off per se was reflected in differential recruitment of dorsolateral frontoparietal and striatal regions. In contrast, the affective modulation of stability/flexibility shifts was mirrored, unexpectedly, by neural responses in ventromedial prefrontal and posterior cingulate cortices, core nodes of the "default mode" network. Our results demonstrate that the affective modulation of cognitive control depends on the performance contingency of the affect-inducing stimuli, and they document medial default mode regions to mediate the flexibility-promoting effects of performance-contingent positive affect, thus extending recent work that recasts these regions as serving a key role in on-task control processes.
\end{abstract}

\section{Introduction}

Successful navigation through our environment requires the ability to focus on the current task while simultaneously being capable of switching to a more urgent task or respond to unexpected events. This optimal balancing between stability (exploitation) and flexibility (exploration) plays a fundamental role in our daily decision making (Gittins and Jones, 1974; Cohen et al., 2007) and anomalies in this balance are central to various clinical disorders (Frank et al., 2009; Strauss et al., 2011). It is widely thought that affective processes modulate this stability/flexibility trade-off (Easterbrook, 1959; Isen, 2000). However, the nature of this modulation is presently equivocal.

One attractive hypothesis for affective modulation of cognitive stability/flexibility is based on the idea that positive (negative) stimuli facilitate (suppress) the gating of new information

\footnotetext{
Received March 20, 2013; revised Aug. 26, 2013; accepted Sept. 19, 2013.

Author contributions: S.B., J.A.K., F.M.K., R.M.K., W.N., and T.E. designed research; S.B., J.A.K., and F.M.K. performed research; S.B., J.A.K., and F.M.K. analyzed data; S.B., J.A.K., F.M.K., R.M.K., W.N., and T.E. wrote the paper.

This research was funded by National Institute of Mental Health Award R01MH087610 (T.E.). S.B. and W.N. were supported by FWO-Vlaanderen G.0098.09N and FW0 Travel Grant V418212N.

The authors declare no competing financial interests.

Correspondence should be addressed to Senne Braem, Department of Experimental Psychology, Henri DunantIaan 2,9000 Ghent, Belgium. E-mail:Senne.Braem@Ugent.be.

DOI:10.1523/JNEUROSCI.1208-13.2013

Copyright $\odot 2013$ the authors $\quad 0270-6474 / 13 / 3316961-10 \$ 15.00 / 0$
}

into prefrontal working memory or task-set representations (Ashby et al., 1999; Braver and Cohen, 2000). While some studies have supported this idea (van Steenbergen et al., 2009, 2012), others have produced contradictory results (Gable and HarmonJones, 2008; Padmala et al., 2011). Here, we tested the hypothesis that performance contingency is a key factor in determining the exact nature of these emotion-cognition interactions.

Specifically, we predicted that performance-contingent positive affect indicates that task goals are being met successfully, loosening task focus toward a more exploratory mode (Carver, 2003; Gable and Harmon-Jones, 2011, van Steenbergen et al., 2009), while performance-contingent negative affect promotes the need for stabilizing the present task-set, directing attention toward the task (van Steenbergen et al., 2012). In contrast, Gable and Harmon-Jones (2008) demonstrated how presenting noncontingent positive pictures can speed local (relative to global) target detection, suggesting that positive pictures rouse an "approach motivation," inducing a narrower (exploitation) task focus, while noncontingent negative pictures have been argued to shift attention away from the task (Padmala et al., 2011). We tested these predictions by presenting negative or positive pictures following trials of a task-switching experiment that used bivalent stimuli, which could be either congruent or incongruent (i.e., conflict inducing). Importantly, the presentation of the affective stimuli was either performance contingent, or not. We 
tested this manipulation on a single, direct metric of the stability/ flexibility trade-off, namely, the conflict-modulated task-switch cost ("Goschke effect"), referring to a larger switch cost following incongruent trials than following congruent trials (Goschke, 2000). This effect is thought to reflect the detrimental impact of conflict-induced enhancement of task-focus (i.e., increased stability; Botvinick et al., 2001) on the cognitive flexibility required for a task-switch. Thus, a smaller (larger) Goschke effect reflects more flexibility (stability).

While extant neuroscience models of affect-control interactions (Ashby et al., 1999; Gray, 2001; Pessoa, 2008, 2009; Shackman et al., 2011) do not incorporate the factor of performance-contingency (Chiew and Braver, 2011), we anticipated that the predicted interaction between affect, performance contingency, and control would manifest as a modulation of a frontostriatal network that has been theoretically (Braver and Cohen, 2000; Frank et al., 2001) and empirically (Forstmann et al., 2010; D’Ardenne et al., 2012) implicated in the updating of task-set representations.

\section{Materials and Methods}

Participants. Thirty-five participants took part in this study (mean age $=$ 26 years, $\mathrm{SD}=6 ; 17$ female). All participants had normal or corrected to normal vision, and were right-handed as assessed by the Edinburgh Handedness Inventory. They gave their informed written consent and reported no current or history of neurological, psychiatric, or major medical disorder. Every participant was paid $\$ 35$ for participating, as well as an extra $\$ 16$ during the task as part of the experiment's reward schedule (which will be explained below). The work has been completed with the approval of the Duke University Health System Institutional Review Board.

Stimuli. The task stimuli were the numbers $1,2,3,4,6,7,8$, or 9 , centrally presented in isoluminant green or blue. Fifty positive and fifty negative pictures were selected from the International Affective Pictures System (IAPS; Lang et al., 2008) database, matched on their semantic content (e.g., crying baby vs smiling baby, cute animal vs dangerous animal, sunset vs thunderstorm). All stimuli were presented against a black background on a back-projection screen, which participants viewed in a mirror mounted to the head coil. This setup simulated a viewing distance of $80 \mathrm{~cm}$, resulting in picture sizes of $10^{\circ}$ wide and $7.4^{\circ}$ high and number stimuli of $\sim 0.4^{\circ}$ wide and $0.8^{\circ}$ high. Responses were registered via a magnetic resonance (MR)-compatible response box (Current Designs), which was placed on the participant's abdomen (oriented perpendicular to the length of their body). The task required the participants to press the leftmost or rightmost button (out of four horizontally aligned response buttons) with their left or right hand, respectively. Stimuli presentation and response registration were performed using Presentation software (Neurobehavioral Systems).

Procedure. The goal of the study design was to assess the effect of affective stimuli (positive or negative IAPS pictures) on cognitivecontrol processes involved in switching between conflicting task goals, depending on whether the affective stimuli were tied to task performance or not. To this end, we presented affective picture stimuli (positive vs negative) tied to monetary gains following each trial of a standard task-switching protocol. Importantly, in one group of subjects ("nonperformancecontingent condition"), these affective stimuli were unrelated to performance, whereas in another, closely matched group of subjects ("performance-contingent condition"), affective feedback (and monetary gain) was dependent on performance speed and accuracy. Specifically, participants were informed that task stimuli would be followed by a randomly chosen positive or negative picture and that positive pictures were associated with 10 cents monetary gain. In the nonperformance-contingent condition, the instructions explicitly mentioned that the picture presentation was unrelated to task performance. In the performance-contingent condition, participants were informed that there would be no picture presentation (and therefore no chance of gaining money) after incorrect or too slow responses. Finally, response speed and accuracy were stressed in both conditions. Importantly, in addition to the difference in instructions concerning the pic- tures, and the absence of pictures after inaccurate or slow responses (exceeding the $1500 \mathrm{~ms}$ deadline) in the performance-contingent condition, there were no differences between the two conditions.

The task switching paradigm itself required participants to carry out either a parity or magnitude judgment on the digit stimuli depending on the color in which each digit was presented. Specifically, when the digit was presented in blue, subjects had to press a left-hand button if the number was odd and a right-hand button if the number was even. When the number was presented in green, subjects had to press left if it was smaller than five and right if it was bigger than five. These task-color associations were counterbalanced across participants. A random serial presentation of these stimuli (excluding number repetitions) created task sequences of task repetitions and task switches, allowing us to assess typical task-switch costs. Moreover, because the digit stimuli were bivalent, that is, each stimulus was associated with possible responses in both task-sets, and stimulus categories in the different task-sets were mapped onto overlapping response sets, each stimulus could be either congruent (i.e., it would produce the same manual response in both task-sets) or incongruent (it would render different responses in the two task-sets). Overall, these manipulations produced a factorial mixed-effects design, which we analyzed according to the following five factors of interest: the within-subject factors of task sequence (task-repetition vs task-switch); previous trial congruency (congruent vs incongruent); current trial congruency (congruent vs incongruent trial); and the valence of the picture (positive vs negative) that preceded the current trial (we call this factor "preceding valence" from here onward); and finally, the betweensubjects factor of contingency condition (performance-contingent vs nonperformance-contingent).

As shown in Figure $1 A$, each trial began with a colored digit stimulus, presented $0.6^{\circ}$ above a central fixation dot (which remained on-screen throughout the task) for $200 \mathrm{~ms}$. There was a maximum response time (RT) window of $1500 \mathrm{~ms}$, starting from stimulus onset. Stimulus presentation was followed by a variable stimulus-picture interval. Thereafter, an IAPS picture was presented above the central fixation dot for $500 \mathrm{~ms}$, which was followed by another variable picture-stimulus interval until the next digit stimulus was presented. Both variable time intervals were independently randomized and were drawn from a pseudo-exponential distribution (50\% lasted $3 \mathrm{~s} ; 25 \%, 3.5 \mathrm{~s} ; 12 \%, 4 \mathrm{~s} ; 7 \%, 4.5 \mathrm{~s}$; and 6\%, $5 \mathrm{~s}$ ), resulting in a mean time interval of $\sim 3.5 \mathrm{~s}$. This jittering allowed us to independently estimate activations associated with each digit and picture stimulus (Ollinger et al., 2001). Importantly, in the performancecontingent condition, the picture did not follow the response if the subjects had not responded correctly or within the response time window. Instead, the fixation dot was presented for $500 \mathrm{~ms}$.

After a short practice block of 32 trials outside the scanner, participants performed five experimental blocks during scanning. Each block contained 64 trials. There was a short break between blocks in which the participants could see their updated score. Each of the 32 stimuluspicture combinations ( 8 numbers $\times 2$ task colors $\times$ picture valence) was presented 10 times in a randomized order and IAPS pictures were randomly chosen from the appropriate valence group, but never reoccurred within a block. On average, participants in the performance-contingent condition would mostly end up with a slightly smaller amount than people in the nonperformance-contingent condition (who always won the maximum amount: \$16). However, after the experiment, participants received the same maximum amount possible, regardless of their outcome or contingency condition.

Behavioral data analyses. Three participants were excluded from analyses because of too few registered responses $(26,30$, and $51 \%$ of their responses exceeded the response registration deadline). The remaining 32 participants had a mean of $3.7 \%(\mathrm{SD}=4 \%)$ of unregistered responses. There was an equal amount of men and women (eight women and eight men) assigned to each condition and age did not differ significantly (nonperformance-contingent condition: mean age $=25, \mathrm{SD}=4 \%$; performance-contingent condition: mean age $=27, \mathrm{SD}=7 \%), t_{(1,30)}=$ $1.187, p>0.1)$. Before analyses, trials following an error and the first trial of each block were removed. We performed an ANOVA with the four within-subject factors task sequence (repetition vs switch), current trial 
congruency (congruent vs incongruent), previous trial congruency and preceding valence (positive vs negative picture), and the betweensubjects factor of contingency condition (performance-contingent vs nonperformance-contingent) on correct trial RTs and error rates.

Questionnaires. All participants completed the Behavioral Inhibition System/Behavioral Activation System (BIS/BAS) questionnaire (Carver and White, 1994) and the Positive and Negative Affect Scale (PANAS; Watson et al., 1988). These scores were used to ensure that differential effects obtained for the between-subjects factor could not be attributable to overall group differences in mood or punishment/reward sensitivity.

Functional MRI data acquisition. Imaging was conducted on a GE Discovery MR750 system at $3.0 \mathrm{~T}$ using a standard head coil. We acquired functional images parallel to the AC-PC plane with a T2*-weighted single-shot gradient EPI sequence of 36 contiguous axial slices (repetition time, $2000 \mathrm{~ms}$; echo time, $28 \mathrm{~ms}$; flip angle, $90^{\circ}$; field of view, 192 $\mathrm{mm}$; array size, $64 \times 64$ ) with $3 \mathrm{~mm}$ thickness and $3 \times 3 \mathrm{~mm}$ in-plane resolution. Structural images were acquired with a T1-weighted FSPGR axial scan using a 3D inversion recovery prepared sequence, recording 120 slices of $1 \mathrm{~mm}$ thickness and in-plane resolution of $1 \times 1 \mathrm{~mm}$.

fMRI data analysis. All preprocessing steps and statistical analyses were performed using SPM8 (http://www.fil.ion.ucl.ac.uk/spm/software/spm8/). Functional data were slice-time corrected and spatially realigned to the first volume of the task. The structural image was normalized to the Montreal Neurological Institute (MNI) template brain (resampled voxel size $2 \mathrm{~mm}^{3}$ ). The normalization parameters were then applied to the functional images to ensure an anatomically informed normalization. The first five volumes of each run in which no stimulation occurred were discarded before estimating statistical models. A $128 \mathrm{~s}$ temporal highpass filter was applied to the data. Temporal autocorrelations were estimated using restricted maximum likelihood estimates of variance components with a first-order autoregressive model, and the resulting nonsphericity was used to form maximum likelihood estimates of activations. A spatial smoothing filter of $8 \mathrm{~mm}$ full-width at half maximum was applied. Event-related regressors convolved with a canonical hemodynamic response function were created corresponding to the stimulus onsets and picture onsets of each trial defined by the same factors as the behavioral data analyses. More specifically, both picture- and stimuluslocked onset regressors were defined by the congruency of the present trial, the congruency of the previous trial, and the task sequence status (task repetition or task switch). Furthermore, the regressors of picture onsets were also defined by the picture valence of the current trial, while the regressors of stimulus onsets were defined by the picture valence of the preceding trial (because the picture of the current trial is only presented after stimulus onset). Error trials, trials following an error, and the first trial of each run were modeled separately as nuisance variables. Single-subjects contrasts on stimulus-locked regressors were calculated to establish the hemodynamic correlates of the task-switch cost (switch $>$ repetition) and the Goschke effect (task-switch cost following incongruent trials $>$ task-switch cost following congruent trials). Group effects were assessed by submitting the individual contrast images to voxelwise one-sample $t$ tests (random-effects model). Between-group differences in the modulation of the Goschke effect by previous picture valence, as well as the effect of picture valence on picture-locked regressors, were assessed by submitting the individual contrast images to voxelwise independent two-sample $t$ tests.

To control for false positive rates, combined voxel activation intensity and cluster extent thresholds corrected for multiple comparisons were determinedbyusing3dClustSim(http://afni.nimh.nih.gov/pub/dist/doc/ program_help/3dClustSim.html). This widely used correction method is applied to statistical contrast images at the group level and estimates the probability of observing false positive (random fields of noise) clusters of a given size, as a function of a given voxelwise $p$ value. The $3 \mathrm{dCl}$ ustSim program considers the size of the image (number of voxels), the voxelwise statistical values, and the spatial correlations over voxels (spatial smoothness) and runs a user-specified number of Monte Carlo simulations to generate an appropriate null-distribution. Here, we ran 10,000 Monte Carlo simulations taking into account the whole-brain search volume and the estimated spatial smoothness of each axis of the respective group SPMs to generate probability estimates of a random field of noise producing a cluster of voxels of a given extent for a set of voxels passing a specific voxelwise $p$ value threshold, which we set at 0.005 for all analyses. Given this voxelwise threshold, the simulations determined that cluster sizes of 215-252 voxels, depending on the specific analysis, corresponded to a combined threshold of $p<0.05$ (corrected).

Region of interest analyses. For evaluation of interaction effects, we extracted mean $\beta$ estimates from empirically defined regions of interest (ROIs), using MarsBaR software (http://marsbar.sourceforge.net/). Specifically, we extracted for each participant activation estimates from a 5 $\mathrm{mm}$ radius sphere centered on activation maxima in the contrast of interest and submitted the resulting values to statistical tests.

\section{Results}

\section{Behavioral data}

Mean accuracy and RTs did not differ between the performancecontingent (accuracy $=89.9 \%$; mean RT $=834 \mathrm{~ms}$ ) and nonperformance-contingent condition (accuracy $=88.4 \%$; mean $\mathrm{RT}=833 \mathrm{~ms}$ ) and there were no differences in punishment/reward sensitivity scores (BIS/BAS) or mood scales (PANAS) between both conditions (all $\left.t_{(1,30)}<1\right)$.

As expected, there was a significant task-switch cost, in both $\operatorname{RTs}\left(F_{(1,30)}=92.853, p<0.001\right)$ and error rates $\left(F_{(1,30)}=43.175\right.$, $p<0.001)$, indicating higher RTs and error rates when a task alternated ( $870 \mathrm{~ms}, 9.8 \%$ errors) as opposed to when the task repeated $(807 \mathrm{~ms}, 5.5 \%)$. We also observed a typical congruency effect, which was expressed in higher RTs $\left(F_{(1,30)}=94.678, p<\right.$ $0.001)$ and higher error rates $\left(F_{(1,30)}=49.604, p<0.001\right)$ for incongruent trials ( $882 \mathrm{~ms}, 12.6 \%$ ) as opposed to congruent trials (795 ms, 2.7\%). Additionally, we observed a main effect of previous congruency in $\operatorname{RTs}\left(F_{(1,30)}=10.872, p<0.01\right)$ and a trend in error rates $\left(F_{(1,30)}=3.824, p=0.06\right)$ : trials following an incongruent trial were slower and less accurate $(847 \mathrm{~ms}, 8.3 \%)$ than trials following a congruent trial $(831 \mathrm{~ms}, 6.9 \%)$. Furthermore, there was a significant interaction between congruency and task sequence in both RTs $\left(F_{(1,30)}=11.378, p<0.01\right)$ and error rates $\left(F_{(1,30)}=23.474, p<0.01\right)$, showing a greater congruency effect for task-switch, than task-repeat trials. As expected, a significant Goschke effect was observed in the error rates (two-way interaction between previous congruency and task sequence; $F_{(1,30)}=$ 12.361, $p<0.01$ ), indicating a higher task-switch cost following incongruent trials $(6.1 \%)$, as opposed to congruent trials $(2.6 \%)$. This effect was not observed in the RTs. However, most importantly, a four-way interaction in RTs between condition, task sequence, previous congruency, and preceding valence indicated diverging effects of the IAPS pictures on cognitive control, dependent on the contingency condition $\left(F_{(1,30)}=10.407, p<0.01\right.$; Fig. $1 B, C)$. No other main effects or interactions reached significance $($ all $p>0.1)$.

To further investigate the four-way interaction involving the effect of IAPS picture presentation on cognitive control, we examined each contingency condition separately. In the performance-contingent condition, there was a significant threeway interaction between task sequence, previous congruency, and preceding valence $\left(F_{(1,15)}=8.350, p<0.05\right)$. There was a tendency for an increased task-switch cost after incongruent trials, as opposed to after congruent trials, when preceded by a negative picture (task-switch cost after incongruent trials minus the task-switch cost after congruent trials $=25 \mathrm{~ms} ; F_{(1,15)}=$ 4.271, $p=0.056$ ), but not when preceded by a positive picture $\left(-23 \mathrm{~ms} ; F_{(1,15)}=1.637, p>0.1\right)$. In contrast, in the nonperformance-contingent condition, there was a marginally significant three-way interaction between task sequence, previous congruency, and previous valence in the opposite direction $\left(F_{(1,15)}=3.616, p=0.077\right)$, as the Goschke effect could be ob- 



Figure 1. General paradigm and behavioral results. A, Trial procedure. Participants had to respond to either the parity (odd or even) or magnitude (larger or smaller than five) of the presented digit, depending on its color (blue or green). A randomly chosen positive or negative picture was presented after each stimulus, except in the performance-contingent condition, where a black screen was shown if the preceding response to the task stimulus was incorrect or too slow $(>1500 \mathrm{~ms})$. In both conditions, each positive picture presentation was associated with a $\$ 0.1 \mathrm{monetary}$ gain. The background color in the experiment was black. B, Group mean RTs for each contingency condition separately. Dotted lines indicate task switches and full lines indicate task repetitions. Prev con and prev incon indicate that the trial was preceded by a congruent and incongruent trial, respectively. The results demonstrate how the conflict-enhanced task-switch cost, as an index of cognitive stability, is counteracted after positive affect (green) in the performance-contingent condition, and after negative affect (orange) in the nonperformance-contingent condition. C, The bars represent the respective conflict-enhanced task-switch costs (i.e., Goschke effects) for each valence and contingency condition separately (calculated by subtracting the task-switch cost after congruent trials from the task-switch cost after incongruent trials). All error bars indicate \pm 1 SEM.

served following positive pictures (38 ms; $F_{(1,15)}=5.256, p<$ $0.05)$, but not following negative ones $\left(-7 \mathrm{~ms} ; F_{(1,15)}<1\right)$. In other words, the typical conflict modulated task-switch cost (Goschke effect) was observed following negative pictures (but not positive ones) in the performance-contingent group and following positive pictures (but not negative ones) in the nonperformance-contingent group.

As predicted, these results show how the affective modulation of the Goschke effect is defined by the performance contingency of the affective stimuli. Specifically, the Goschke effect, as a measure of cognitive stability (at the cost of cognitive flexibility), was counteracted after performance-contingent positive pictures, but enhanced after performance-contingent negative pictures. This is consistent with the idea that positive affect following an achieved goal signals a comfortable environment, where task focus is loosened toward a more exploratory mode (Carver, 2003; Gable and Harmon-Jones, 2011, van Steenbergen et al., 2009), while performance-contingent negative affect calls for enhanced cognitive stability (van Steenbergen et al., 2012). In contrast, noncontingent positive pictures enhanced the Goschke effect, in line with the observation that noncontingent (unexpected) positive pictures induce a narrower task focus (Gable and Harmon-Jones, 2008). Noncontingent negative pictures counteracted the Goschke effect, suggesting negative pictures triggered an avoidance state, shifting attention away from the task (Padmala et al., 2011).
We next turned to the fMRI data to determine the neural mediators of this affective modulation of cognitive control.

\section{fMRI data: task-switching and its modulation by previous congruency}

All activations we report are whole-brain corrected at $p<0.05$ (see Materials and Methods). We begin by analyzing neural substrates of task-switching to provide a point of contact with the previous literature, and then move on to assess the neural correlates of the Goschke effect, that is, activations associated specifically with updating/shifting a task-set in opposition to recently activated task-set stabilization processes. As displayed in Figure $2 A$ and Table 1 , a random-effects analysis of the fMRI data on the task-switch cost (task-switch $>$ task-repetition) uncovered a dorsolateral frontoparietal network, as well as the insulae, right thalamus, posterior cingulate cortex, and dorsomedial frontal cortex, consistent with typical findings from the task-switching literature (Sohn et al., 2000; Brass and von Cramon, 2002; Braver et al., 2003).

Next, having identified the brain regions involved in taskswitching per se, we investigated how previous trial congruency modulated task-switching activity, assessing the neural correlates of the behavioral phenomenon of enhanced switch costs following an incongruent trial (Goschke, 2000). As hypothesized, our results show the neural signature of the Goschke effect (switch- 

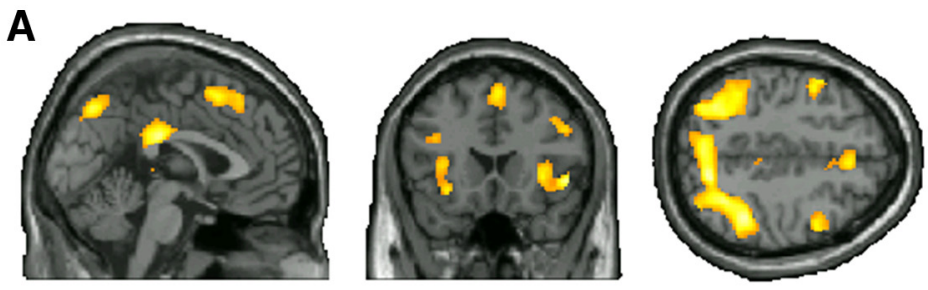

B
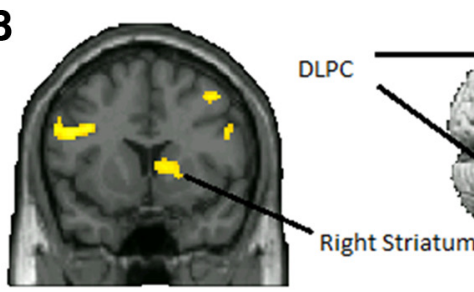

C
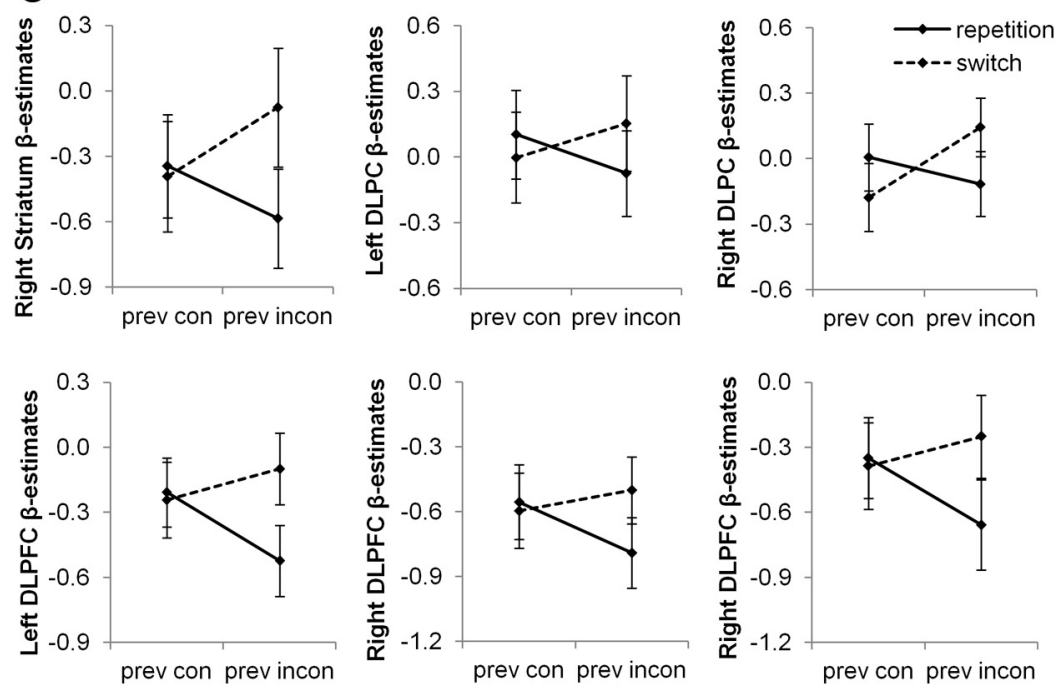

Figure 2. $\quad A$, The regions identified by the stimulus-locked task-switch cost (task-switch $>$ task-repetition) regression analysis are plotted at $p<0.05$ (corrected) on sagittal $(x$ 0), coronal ( $y 20)$, and axial ( $z$ 46) of an individual brain in MNI space. $\boldsymbol{B}$, The regions identified by the stimulus-locked Goschke effect (switch cost after incongruent trials $>$ switch cost after congruent trials) regression analysis are plotted at $p<0.05$ (corrected) on coronal ( $y$ 12) and cortex surface of an individual brain in MNI space. $\boldsymbol{C}$, Group mean activations for switch and repetition trials ( $\beta$ estimates \pm SEM) across contingency conditions in the right dorsal striatum, left and right dorsolateral prefrontal cortex (DLPFC), and left and right dorsolateral parietal cortex (DLPC) are plotted for trials following congruent and incongruent trials (all $F_{(1,30)}>10.8, p<0.005$ ). Note that the line graphs and error bars are displayed for the purpose of visual presentation (not statistical inference) of the patterns of activation means and variance observed in the ROls that were identified based on the statistical inference drawn by the whole-brain corrected group analysis.

effort for set-shifting or task-set updating after incongruent trials. However, as indicated by our behavioral results, picture valence, depending on performance contingency, is an important determinant of the conflict-modulated switch cost, attenuating the cost following performance-contingent positive stimuli, and enhancing it following noncontingent positive stimuli. To identify the neural mediators of these modulations, we next searched for brain regions where the expression of the Goschke effect varied as a function of picture affect and performance contingency.

\section{fMRI data: performance contingency and affective modulation of cognitive control}

Having established our cognitive-control effect of interest, both at the behavioral and neural level, we now turn to its modulation by affect and performance contingency. As predicted, the RT analyses demonstrated that the affective modulation of the Goschke effect was determined by the performance contingency of the affective pictures. However, contrary to our expectations that this modulation would impinge directly on the frontostriatal network detected above (Fig. 2B), a wholebrain analysis of this four-way interaction documented instead the involvement of the posterior cingulate cortex (PCC), the ventromedial prefrontal cortex (vmPFC) including the pregenual anterior cingulate, the right middle temporal gyrus (rMTG), and superior medial frontal cortex (sMFC) in this modulation (Fig. $3 A$, Table 1).

These brain regions' activity patterns show an inverse relationship with the behavioral expression of the Goschke effect: neural task-switch costs were highest in conditions where behavioral costs were smallest in terms of RTs (Fig. 3B). Specif-

cost after incongruent trials $>$ switch-cost after congruent trials) to consist of a modulation of the dorsolateral frontoparietal network and the right dorsal striatum (Fig. 2B, Table 1).

Previous studies (Eslinger and Grattan, 1993; Ragozzino, 2007; McNab and Klingberg, 2008; Forstmann et al., 2010; Kehagia et al., 2010; D'Ardenne et al., 2012) and models (Braver and Cohen, 2000; Frank et al., 2001; O’Reilly and Frank, 2006) have related this corticostriatal network to the updating of task goals and/or stimulus-response associations. Consistent with this prior work, in our task this updating mechanism (promoting cognitive flexibility) enabled participants to shift sets on task alternations (D'Ardenne et al., 2012). In line with this interpretation, the network was furthermore recruited to a greater extent for switch trials that followed an incongruent trial (Fig. 2C), which are known to render a change in task-set (i.e., updating) particularly effortful (Goschke, 2000; Brown et al., 2007; Verguts and Notebaert, 2009). In other words, current task associations or task focus are enhanced after cognitive conflict and therefore require a greater ically, all four regions showed a significant modulation of the Goschke effect in the performance-contingent condition (all Fs $>5.1, p s<0.05)$, in that a neural signature of the Goschke effect (greater task-switch cost after incongruent trials as opposed to congruent trials) could be observed after positive pictures, which was reversed after negative pictures (Fig. $3 C$ ), while reaction times showed a Goschke effect after negative pictures, but not after positive pictures (cf. Fig. 1C). Both the PCC and rMTG also showed a significant modulation of the Goschke effect in the noncontingent condition, both $F s>5.2$, ps $<0.05$. In the vmPFC, this interaction reached marginal significance $\left(F_{(1,15)}=\right.$ 4.147, $p=0.06$ ), but the sMFC showed no such modulation in the noncontingent condition $\left(F_{(1,15)}=1.413, p>0.1\right)$.

Since vmPFC and PCC have previously been argued to form core nodes of a "resting" (task-negative; Fox et al., 2005) or "default mode" network (Gusnard et al., 2001; Raichle et al., 2001), it could be argued that these regions simply become more active whenever control demands are relatively low. If the latter inter- 


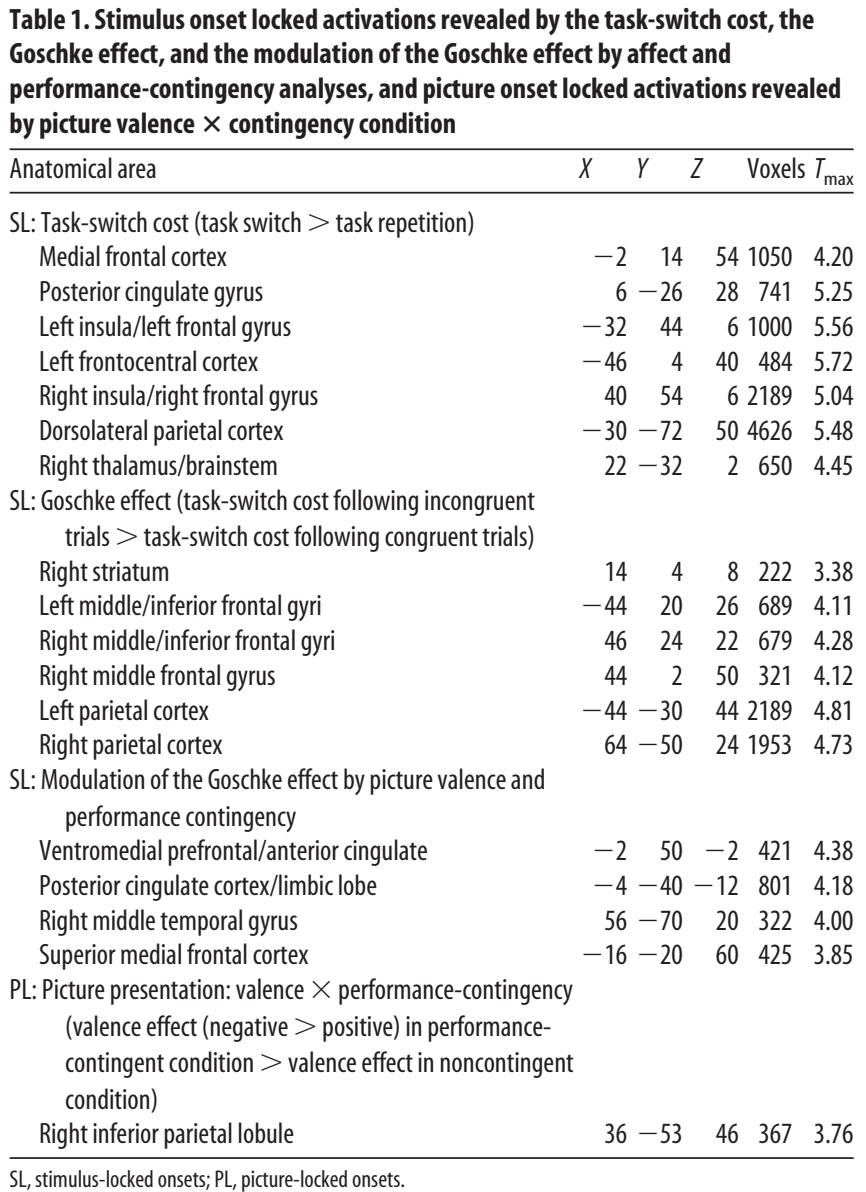

SL, stimulus-locked onsets; PL, picture-locked onsets.

pretation was correct, activity in these regions should be higher for any comparison between a less demanding (lower RT) with a more demanding (higher RT) condition. However, none of the regions showed a main effect of task-switch or congruency (despite highly significant RT effects; all Fs $<1.4$, ps $>0.25$ ). This renders an explanation in terms of a global inverse relationship with task demands implausible. Instead, our data suggest that these regions were differentially recruited to attenuate taskswitch costs depending on previous congruency and the affectinduced cognitive control mode (exploration vs exploitation). For example, positive performance-contingent affect promoted cognitive flexibility in a context-dependent manner, by enhancing this network's activity on task-alternations following incongruent trials (when the enhancement of cognitive flexibility is most desirable). This perspective is consistent with the involvement of the PCC and the vmPFC in other recent investigations of the affective modulations of cognitive control (Subramaniam et al., 2009; Hart, Green et al., 2010; Sakaki and Niki, 2011) and, more broadly, is supportive of the notion that these medial wall regions may serve a key role in endogenously driven switches in behavioral policies in response to sudden environmental changes (Pearson et al., 2011).

\section{fMRI data: performance contingency and the processing of stimulus valence}

Last, the jittered time-interval between picture and stimulus presentation also allowed us to identify brain regions differentially activated by affect as a function of performance contingency. Consistent with our behavioral data, we hypothesized that positive affect experienced after a goal has been achieved induces an exploratory state, while noncontingent (unexpected) positive affect narrows task-focus. Conversely, experiencing negative affect after a goal has been achieved calls for an enhanced task-focus, while noncontingent (unexpected) negative affect disturbs task focus. We tested for the neural substrates of this differential modulation of attentional scope by picture valence and performance contingency by analyzing activation time locked to picture presentation, but before subsequent task-performance (trial onset). The analysis investigating this (picture-locked) valence $\times$ contingency condition contrast revealed activation in the right inferior parietal lobe (rIPL; Fig. 4A, Table 1). Post hoc t tests of rIPL activity within each performance-contingency condition show that this interaction was due to the fact that positive pictures, relative to negative ones, significantly deactivated this region in the performance-contingent condition $\left(t_{(15)}=3.0, p<0.01\right)$ and, marginally significant, enhanced this region's activity in the noncontingent condition $\left(t_{(15)}=1.9, p=0.083\right.$; Fig. $\left.4 B\right)$. These data suggest an important role for the rIPL in translating external cues into internal processing adjustments. Concordant with these data, a recent literature review proposes that IPL is involved in flexibly reconfiguring behavior between two different modes of attention: maintaining control on current task-goals, on the one hand, and flexibly switching to new external demands, on the other hand (Singh-Curry and Husain, 2009). This perspective on the present finding is also consistent with our behavioral data, demonstrating a differential impact of picture valence on cognitive stability/flexibility, depending on performance contingency.

\section{Discussion}

Investigating the role of performance contingency in defining affective modulations of cognitive control, we report four novel findings. First, in line with our predictions, positive (negative) affective stimuli promoted cognitive flexibility (stability) when performance-contingent, but enhanced stability (flexibility) when not performance-contingent. Second, the Goschke effect, indexing the stability/flexibility trade-off, was associated with corticostriatal activations, displaying a neural switch cost after incongruent but not after congruent trials. Third, and contrary to expectations, the performance-contingency-dependent affective modulation of this effect was mediated by a different network, centered on the vmPFC and the posterior cingulate. Last, we documented the rIPL to play an important role in setting up this contingency-dependent processing of affective stimuli. We discuss these findings in turn.

By explicitly manipulating performance contingency, we demonstrated how this factor determined the impact of affect on cognitive control. Previous studies did not manipulate, or were unclear about, the performance contingency of affective stimuli. For example, affective stimuli were sometimes described as "reward signals" (immediately following response and accompanied by monetary gain), but were also presented following erroneous responses (van Steenbergen et al., 2009, 2012), rendering their interpretation ambiguous (Dreisbach and Fischer, 2012). By varying performance contingency, we confirmed that performancerelevant positive affect enhances cognitive flexibility (van Steenbergen et al., 2009, 2012), consistent with the hypothesis that positive stimulus presentation after an achieved goal signals comfortable task performance, such that a more explorative cognitive mode can be permitted (Gable and Harmon-Jones, 2011). However, it has also been argued (Gable and Harmon-Jones, 2011) that the popular hypothesis of positive affect-induced cognitive flexibility (Ashby et al., 1999; Dreisbach, 2006) may be restricted to blockwise mood inducements (Dreisbach and Goschke, 2004) 
A

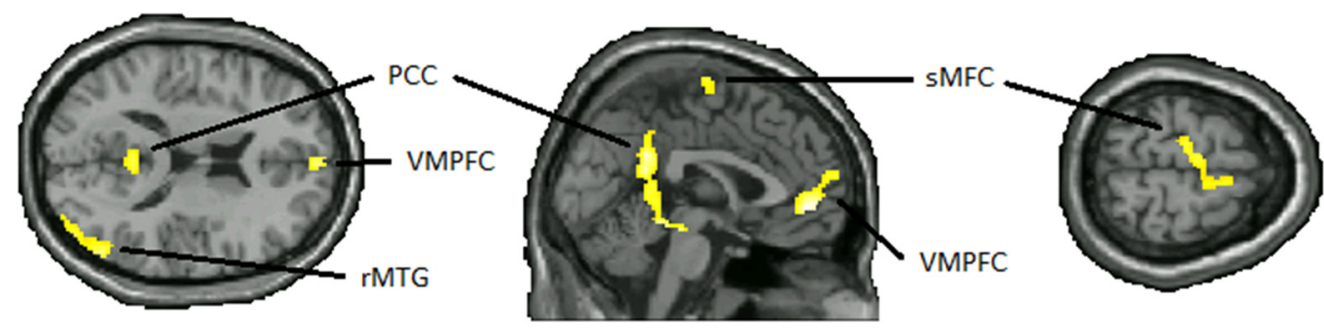

B

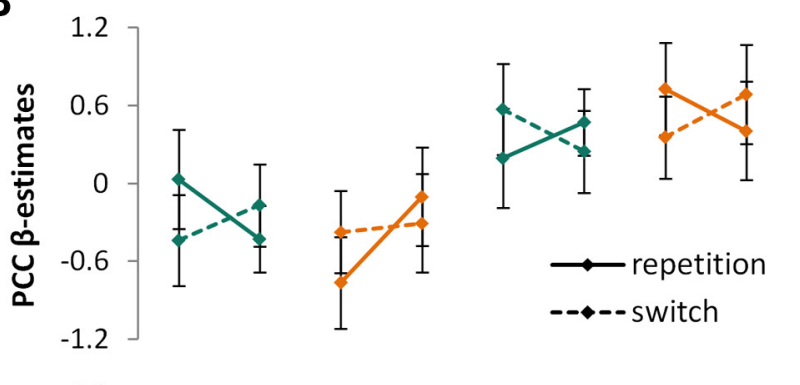

C
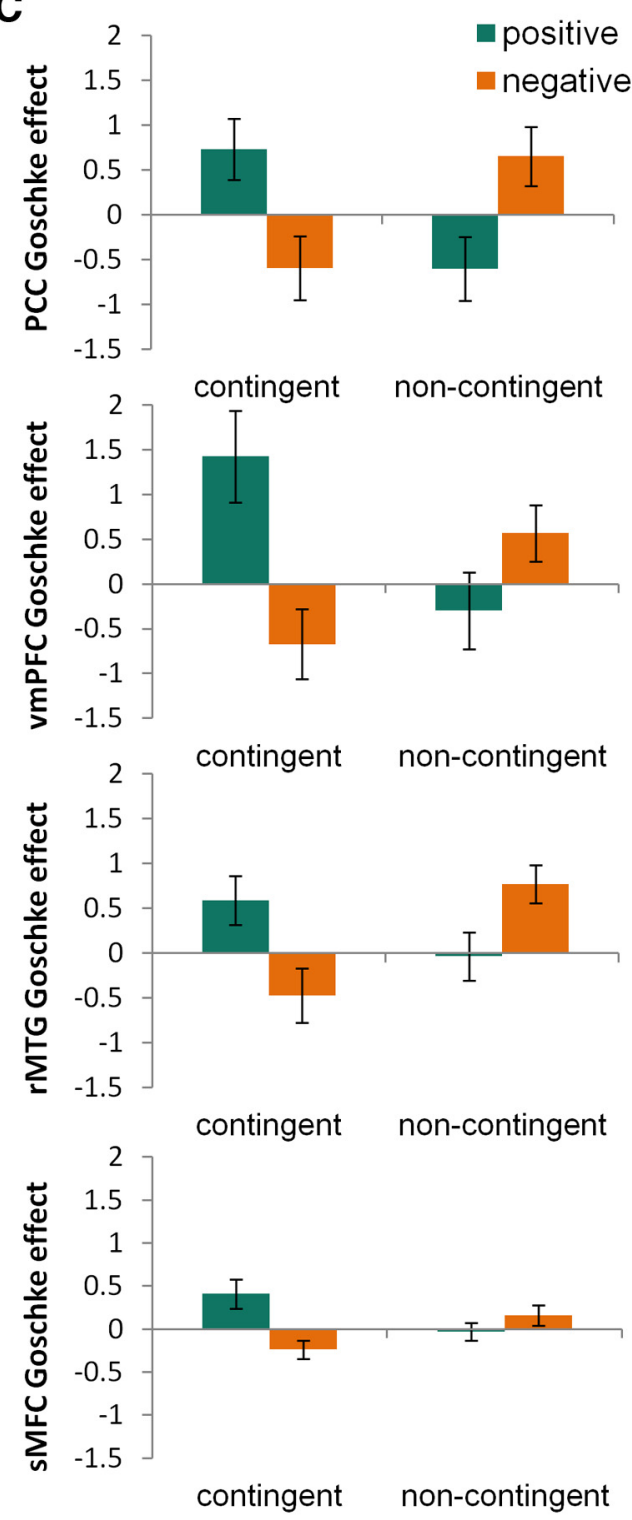

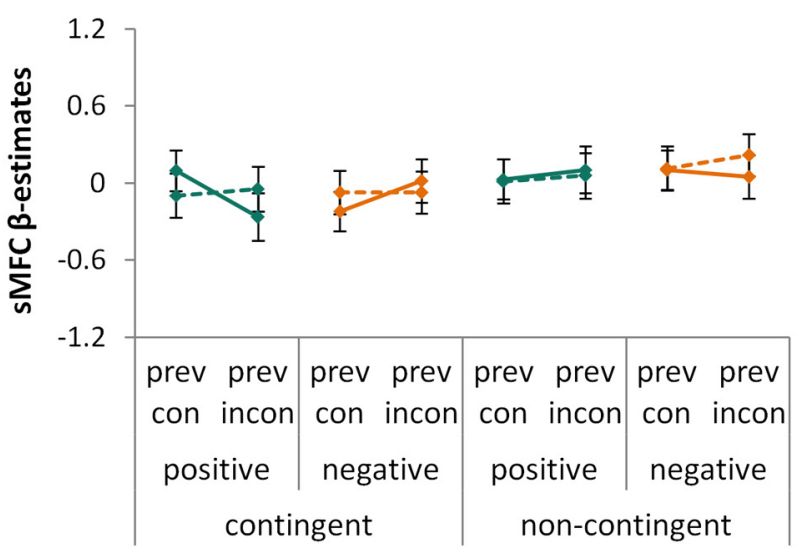

Figure 3. $A$, The regions identified by the modulation of the stimulus-locked Goschke effect by picture valence and contingency condition regression analysis are plotted at $p<0.05$


contingency condition separately in the PCC, vmPFC, rMTG, and sMFC are plotted following congruent or incongruent and positive or negative pictures (all $\left.F_{(1,30)}>10.4, p<0.005\right)$. $C$, Group mean activations for the Goschke effect (switch cost after incongruent trials $>$ switch cost after congruent trials; $\beta$ estimates \pm SEM) for each contingency condition separately in the PCC, vmPFC, rMTG, and SMFC are plotted following positive or negative pictures. Note that the graphs and error bars are displayed for the purpose of visual presentation (not statistical inference) of the patterns of activation means and variance observed in the ROIs that were identified based on the statistical inference drawn by the whole-brain corrected group analysis. 
or post-goal affect (van Steenbergen et al., 2009). Our results corroborate this notion, as performance-unrelated positive pictures actually narrowed attention. This is also in line with the observation that positive pictures facilitate the detection of local (vs global) targets (Gable and Harmon-Jones, 2008; Harmon-Jones and Gable, 2009), possibly by inducing an approach-motivated attentional state: manipulations that increase approach motivation, and individual differences in approach sensitivity, have been shown to modulate this effect (Gable and HarmonJones, 2008).

Additionally, the present results are likely also driven by opposing responses to negative pictures. Specifically, taskrelevant negative stimuli signal a need for stabilizing the present task-set, directing attention toward the task (van Steenbergen et al., 2012), while noncontingent (taskirrelevant) negative pictures pull attention away from the task at hand, thus broadening focus (Padmala et al., 2011). Broadly consistent with this interpretation, Kanske (2012) has stressed the importance of task-relevance for determining the impact of affective stimuli on cognitive control. However, it should be noted that in contrast to the present design (where affect-inducing stimuli preceded task stimuli), the studies in question presented affective stimuli during presentation of the task-relevant stimuli, demonstrating facilitated or impeded task performance dependent on whether these stimuli constituted the target or distractor stimuli (Kanske and Kotz, 2011a,b,c).

In further contextualizing the present data, it is also important to note that our findings were obtained in relation to affectinducing stimuli, i.e., pictures with intrinsic valence. In contrast, other studies using abstract colors or numbers as performancecontingent reinforcement signals (Stürmer et al., 2011; Braem et al., 2012) observed an improved conflict-enhanced task-focus. This discrepancy in findings likely reflects differences in the type of post-goal stimuli used and fits with theoretical work on the motivation of adaptive behavior, suggesting fundamental differences in the impact of affective versus reward feedback (Berridge and Robinson, 2003; Chiew and Braver, 2011; Smith et al., 2011): whereas positive pictures in the current experiment induced post-goal positive affect, signaling a comfortable environment after successful performance (Gable and Harmon-Jones, 2011), the reward signals in the studies of Braem et al. (2012) and Stürmer et al. (2011) likely acted primarily as learning signals, promoting enhanced associations following conflict. In a similar vein, Bijleveld et al. (2012) recently pointed toward different effects of rewards, depending on their perceptibility and how they are processed; while initial (subconscious) reward processing triggers a more rudimentary impact on performance, full (conscious) reward processing will set off more strategic decisionmaking processes and reflections on rewards.

To test the optimal balancing between flexibility and stability, we used a task-switching protocol where both flexibility/exploration (task-switching) and stability/exploitation (conflict control) could be investigated simultaneously. Specifically, we examined the Goschke effect (Goschke, 2000): the enhanced task-switch cost after incongruent as opposed to congruent trials. The associated fMRI data uncovered enhanced task-switch costs after cognitive conflict in a corticostriatal network. This novel finding is concordant with theoretical (Braver and Cohen, 2000; Frank et al., 2001) and empirical work (Eslinger and Grattan, 1993; Ragozzino, 2007; D'Ardenne et al., 2012) suggesting that the striatum sends a gating signal to the dorsolateral prefrontal cortex to update task-set representations. As would be anticipated, this network was recruited on task alternations, especially following incongruent trials, commensurate with the idea that task-set representations are enhanced following incongruent trials, hindering performance on task alternations (Goschke, 2000; Brown et al., 2007).

Next, we examined the contingency-dependent affective modulation of the Goschke effect. It has been suggested that goalrelated positive affect fosters cognitive flexibility via (dopaminergic) striatal gating signals to dorsolateral prefrontal working memory regions (Ashby et al., 1999; Braver and Cohen, 2000; Dreisbach, 2006). Accordingly, we anticipated the interactive effects of affect and performance contingency on cognitive control to play out as a modulation of activity in the frontostriatal circuits discussed above. Instead, this interaction was primarily associated with activations of the PCC and vmPFC, with increased activity observed in the conditions of better behavioral performance. These regions are traditionally considered core nodes of a network that first gained popularity as the default mode network (Gusnard et al., 2001; Raichle et al., 2001). However, recent evidence indicates this network to be highly reactive and tunable (Singh and Fawcett, 2008), closely tied to task control networks (Fair et al., 2008; Sridharan et al., 2008), and important for efficient task performance (Hampson et al., 2006; Leech et al., 2012). Importantly, this network has been shown to play a critical role in facilitating cognitive control for task-switching (Hayden et al., 2010) and, more generally, cognitive flexibility (Pearson et al., 2011; Waltz et al., 2013), as well as the influence of positive mood thereon (Subramaniam et al., 2009; Sakaki and Niki, 2011). Last, the vmPFC has an important role in integrating affective and cognitive processes (Gusnard et al., 2001; Vertes, 2006).

Thus, the present data are commensurate with an affective recruitment, conditioned on performance relevance, of the medial vmPFC-PCC network (which is also subject to dopaminergic modulation; Nagano-Saito et al., 2009; Delaveau et al., 2010; Dang et al., 2012). The model of Pearson et al. (2011) stipulates that, whereas performance in stable cued task paradigms is often well predicted by dorsolateral prefrontal cortices, default mode regions are implicated in versatile task-switching environments, where more than mere explicit task cues predict task performance 
(e.g., the random presentation of positive and negative pictures). Indeed, changes in behavior in the present study were largely predicted by the valence and contingency of the affective pictures, which triggered self-initiated (vs instructed) changes in behavioral policies. Therefore, we propose that the affective trial-totrial modulations of cognitive control are mediated by a modulation of vmPFC/PCC components of the default mode network, where higher activations are associated with self-initiated (switches in) strategy retrieval and selection (Pearson et al., 2009, 2011), driven by an interaction between affect-modulated behavioral policies and conflict-enhanced task associations. However, although our data are consistent with this recent hypothesis by Pearson and et al. (2011), the precise, mechanistic role of these default mode network nodes in regulating the cognitive stability/flexibility trade-off, and the influence of affect thereon, remains to be determined by future investigations.

Last, we investigated how picture processing itself was modulated by the performance-contingency condition. This analysis uncovered the rIPL, consistent with its supposed role in regulating two different modes of attention (Corbetta et al., 2008; Singh-Curry and Husain, 2009): maintaining control on current task-goals on the one hand, and flexibly switching to new external demands on the other (Desmet et al., 2011). We speculate that enhanced activity in the rIPL in the present study may have led to the further enhancement of taskrelevant associations after conflict, promoting a form of cognitive stability; in contrast, this region's deactivation would enhance cognitive flexibility, allowing a better preparation for task-switches after conflict.

In sum, our results demonstrated how performance contingency determines the way affect modulates the balancing between cognitive flexibility and stability. While post-goal performancerelated positive affect promoted cognitive flexibility, post-goal negative affect narrowed attention and enhanced task focus. However, noncontingent affect produced the reverse pattern. Moreover, while task-set updating per se was found to be mediated by frontostriatal circuits, the performance-contingent affective modulation of this cognitive flexibility occurred via recruitment of vmPFC and PCC, thus suggesting a crucial, "task-positive" role in cognitive control for these "default mode network" nodes.

\section{Notes}

Supplemental material for this article is available at http://users.ugent. be/ sbraem/AMCC/pictures.xls. This material has not been peer reviewed.

\section{References}

Ashby FG, Isen AM, Turken AU (1999) A neuropsychological theory of positive affect and its influence on cognition. Psychol Rev 106:529-550. CrossRef Medline

Berridge KC, Robinson TE (2003) Parsing reward. Trends Neurosci 26:507513. CrossRef Medline

Bijleveld E, Custers R, Aarts H (2012) Human reward pursuit from rudimentary to higher-level functions. Curr Dir Psychol Sci 21:194-199. CrossRef

Botvinick MM, Braver TS, Barch DM, Carter CS, Cohen JD (2001) Conflict monitoring and cognitive control. Psychol Rev 108:624-652. CrossRef Medline

Braem S, Verguts T, Roggeman C, Notebaert W (2012) Reward modulates adaptations to conflict. Cognition 125:324-332. CrossRef Medline

Brass M, von Cramon DY (2002) The role of the frontal cortex in task preparation. Cereb Cortex 12:908-914. CrossRef Medline

Braver TS, Reynolds JR, Donaldson DI (2003) Neural mechanisms of transient and sustained cognitive control during task switching. Neuron 39: 713-726. CrossRef Medline

Braver TS, Cohen JD (2000) On the control of control: the role of dopamine in regulating prefrontal function and working memory. In: Attention and performance, Vol. 18 (Monsell S, Driver J, eds), pp 713-737. Cambridge, MA: MIT.

Brown JW, Reynolds JR, Braver TS (2007) A computational model of fractioned conflict-control mechanisms in task-switching. Cogn Psychol 55: 37-85. CrossRef Medline

Carver CS (2003) Pleasure as a sign you can attend to something else: placing positive feelings within a general model of affect. Cogn Emot 17:241261. CrossRef

Carver CS, White TL (1994) Behavioral inhibition, behavioral activation, and affective responses to impending reward and punishment: the BIS/ BAS scales. J Pers Soc Psychol 67:319-333. CrossRef

Chiew KS, Braver TS (2011) Positive affect versus reward: emotional and motivational influences on cognitive control. Front Psychol 2:279. Medline

Cohen JD, McClure SM, Yu AJ (2007) Should I stay or should I go? How the human brain manages the trade-off between exploitation and exploration. Philos Trans R Soc Lond B Biol Sci 362:933-942. CrossRef Medline

Corbetta M, Patel G, Shulman GL (2008) The reorienting system of the human brain: from environment to theory of mind. Neuron 58:306-324. CrossRef Medline

Dang LC, Donde A, Madison C, O’Neil JP, Jagust WJ (2012) Striatal dopamine influences the default mode network to affect shifting between object features. J Cogn Neurosci 24:1960-1970. CrossRef Medline

D’Ardenne K, Eshel N, Luka J, Lenartowicz A, Nystrom LE, Cohen JD (2012) Role of prefrontal cortex and the midbrain dopamine system in working memory updating. Proc Nat Acad Sci U S A 109:19900-19909. CrossRef Medline

Delaveau P, Salgado-Pineda P, Fossati P, Witjas T, Azulay JP, Blin O (2010) Dopaminergic modulation of the default mode network in Parkinson's disease. Eur Neuropsychopharmacol 20:784-792. CrossRef Medline

Desmet C, Fias W, Hartstra E, Brass M (2011) Errors and conflict at the task level and the response level. J Neurosci 31:1366-1374. CrossRef Medline

Dreisbach G (2006) How positive affect modulates cognitive control: the costs and benefits of reduced maintenance capability. Brain Cogn 60:1119. CrossRef Medline

Dreisbach G, Fischer R (2012) The role of affect and reward in the conflicttriggered adjustment of cognitive control. Front Hum Neurosci 6:342. Medline

Dreisbach G, Goschke T (2004) How positive affect modulates cognitive control: reduced perseveration at the cost of increased distractibility. J Exp Psychol Learn Mem Cogn 30:343-353. CrossRef Medline

Easterbrook JA (1959) The effect of emotion on cue utilization and the organization of behavior. Psychol Rev 66:183-201. CrossRef Medline

Eslinger PJ, Grattan LM (1993) Frontal lobe and frontal-striatal substrates for different forms of human cognitive flexibility. Neuropsychologia 31: 17-28. CrossRef Medline

Fair DA, Cohen AL, Dosenbach NU, Church JA, Miezin FM, Barch DM, Raichle ME, Petersen SE, Schlaggar BL (2008) The maturing architecture of the brain's default network. Proc Natl Acad Sci U S A 105:40284032. CrossRef Medline

Forstmann BU, Anwander A, Schäfer A, Neumann J, Brown S, Wagenmakers EJ, Bogacz R, Turner R (2010) Cortico-striatal connections predict control over speed and accuracy in perceptual decision making. Proc Natl Acad Sci U S A 107:15916-15920. CrossRef Medline

Fox MD, Snyder AZ, Vincent JL, Corbetta M, Van Essen DC, Raichle ME (2005) The human brain is intrinsically organized into dynamic, anticorrelated functional networks. Proc Natl Acad Sci U S A 102:9673-9678. CrossRef Medline

Frank MJ, Loughry B, O’Reilly RC (2001) Interactions between frontal cortex and basal ganglia in working memory: a computational model. Cogn Affect Behav Neurosci 1:137-160. CrossRef Medline

Frank MJ, Doll BB, Oas-Terpstra J, Moreno F (2009) Prefrontal and striatal dopaminergic genes predict individual differences in exploration and exploitation. Nat Neurosci 12:1062-1068. CrossRef Medline

Gable PA, Harmon-Jones E (2008) Approach-motivated positive affect reduces breadth of attention. Psychol Sci 19:476-482. CrossRef Medline

Gable PA, Harmon-Jones E (2011) Attentional consequences of pre-goal and post-goal positive affect. Emotion 11:1358-1367. CrossRef Medline

Gittins, JC, Jones DM (1974) A dynamic allocation index for the sequential design of experiments. In Progress in statistics (Gani J, Sarkadi K, Vince I, eds), pp 241-266. North Holland: Amsterdam.

Goschke T (2000) Intentional reconfiguration and involuntary persistence 
in task set switching. In Attention and performance, Volume 18 (Monsell S, Driver J, eds), pp 331-355. Cambridge, MA: MIT.

Gray JR (2001) Emotional modulation of cognitive control: approachwithdrawal states double-dissociate spatial from verbal two-back task performance. J Exp Psychol Gen 130:436-452. CrossRef Medline

Gusnard DA, Akbudak E, Shulman GL, Raichle ME (2001) Medial prefrontal cortex and self-referential mental activity: relation to a default mode of brain function. Proc Natl Acad Sci U S A 98:4259-4264. CrossRef Medline

Hampson M, Driesen NR, Skudlarski P, Gore JC, Constable RT (2006) Brain connectivity related to working memory performance. J Neurosci 26:13338-13343. CrossRef Medline

Harmon-Jones E, Gable PA (2009) Neural activity underlying the effect of approach-motivated positive affect on narrowed attention. Psychol Sci 20:406-409. CrossRef Medline

Hart SJ, Green SR, Casp M, Belger A (2010) Emotional priming effects during Stroop task performance. Neuroimage 49:2662-2670. CrossRef Medline

Hayden BY, Smith DV, Platt ML (2010) Cognitive control signals in posterior cingulate cortex. Front Hum Neurosci 4:223. Medline

Isen AM (2000) Some perspectives on positive affect and self-regulation. Psychol Inquiry 11:184-187.

Kanske P (2012) On the influence of emotion on conflict processing. Front Integr Neurosci 6:42. Medline

Kanske P, Kotz SA (2011a) Emotion speeds up conflict resolution: a new role for the ventral anterior cingulate cortex? Cereb Cortex 21:911-919. CrossRef Medline

Kanske P, Kotz SA (2011b) Emotion triggers executive attention: anterior cingulate cortex and amygdala responses to emotional words in a conflict task. Hum Brain Mapp 32:198-208. CrossRef Medline

Kanske P, Kotz SA (2011c) Positive emotion speeds up conflict processing: ERP responses in an auditory Simon task. Biol Psychol 87:122-127. CrossRef Medline

Kehagia AA, Murray GK, Robbins TW (2010) Learning and cognitive flexibility: frontostriatal function and monoaminergic modulation. Curr Opin Neurobiol 20:199-204. CrossRef Medline

Lang PJ, Bradley MM, Cuthbert BN (2008) International affective picture system (IAPS): affective ratings of pictures and instruction manual. Gainesville, FL, University of Florida: Technical Report A-8.

Leech R, Braga R, Sharp DJ (2012) Echoes of the brain within the posterior cingulate cortex. J Neurosci 32:215-222. CrossRef Medline

McNab F, Klingberg T (2008) Prefrontal cortex and basal ganglia control access to working memory. Nat Neurosci 11:103-107. CrossRef Medline

Nagano-Saito A, Liu J, Doyon J, Dagher A (2009) Dopamine modulates default mode network deactivation in elderly individuals during the Tower of London task. Neurosci Lett 458:1-5. CrossRef Medline

Ollinger JM, Corbetta M, Shulman GL (2001) Separating processes within a trial in event-related functional MRI. II. Analysis. Neuroimage 13:218229. CrossRef Medline

O’Reilly RC, Frank MJ (2006) Making working memory work: a computational model of learning in the prefrontal cortex and basal ganglia. Neural Comput 18:283-328. CrossRef Medline

Padmala S, Bauer A, Pessoa L (2011) Negative emotion impairs conflictdriven executive control. Front Psychol 2:192. CrossRef Medline

Pearson JM, Hayden BY, Raghavachari S, Platt ML (2009) Neurons in posterior cingulate cortex signal exploratory decisions in a dynamic multioption choice task. Curr Biol 19:1532-1537. CrossRef Medline

Pearson JM, Heilbronner SR, Barack DL, Hayden BY, Platt ML (2011) Posterior cingulate cortex: adapting behavior to a changing world. Trends Cogn Sci 15:143-151. CrossRef Medline
Pessoa L (2008) On the relationship between emotion and cognition. Nat Rev Neurosci 9:148-158. CrossRef Medline

Pessoa L (2009) How do emotion and motivation direct executive control? Trends Cogn Sci 13:160-166. CrossRef Medline

Ragozzino ME (2007) The contribution of the medial prefrontal cortex, orbitofrontal cortex, and dorsomedial striatum to behavioral flexibility. Ann N Y Acad Sci 1121:355-375. CrossRef Medline

Raichle ME, MacLeod AM, Snyder AZ, Powers WJ, Gusnard DA, Shulman GL (2001) A default mode of brain function. Proc Natl Acad Sci U S A 98:676-682. CrossRef Medline

Sakaki M, Niki K (2011) Effects of brief viewing of emotional stimuli on understanding of insight solutions. Cogn Affect Behav Neurosci 11:526540. CrossRef Medline

Shackman AJ, Salomons TV, Slagter HA, Fox AS, Winter JJ, Davidson RJ (2011) The integration of negative affect, pain and cognitive control in the cingulate cortex. Nat Rev Neurosci 12, 154-167. CrossRef Medline

Singh KD, Fawcett IP (2008) Transient and linearly graded deactivation of the human default-mode network by a visual detection task. Neuroimage 41:100-112. CrossRef Medline

Singh-Curry V, Husain M (2009) The functional role of the inferior parietal lobe in the dorsal and ventral stream dichotomy. Neuropsychologia 47: 1434-1448. CrossRef Medline

Smith KS, Berridge KC, Aldridge JW (2011) Disentangling pleasure from incentive salience and learning signals in brain reward circuitry. Proc Natl Acad Sci U S A 108:E255-E264. CrossRef Medline

Sohn MH, Ursu S, Anderson JR, Stenger VA, Carter CS (2000) The role of prefrontal cortex and posterior parietal cortex in task switching. Proc Natl Acad Sci U S A 97:13448-13453. CrossRef Medline

Sridharan D, Levitin DJ, Menon V (2008) A critical role for the right frontoinsular cortex in switching between central-executive and default-mode networks. Proc Natl Acad Sci U S A 105:12569-12574. CrossRef Medline

Strauss GP, Frank MJ, Waltz JA, Kasanova Z, Herbener ES, Gold JM (2011) Deficits in positive reinforcement learning and uncertainty-driven exploration are associated with distinct aspects of negative symptoms in schizophrenia. Biol Psychiatry 69:424-431. CrossRef Medline

Stürmer B, Nigbur R, Schacht A, Sommer W (2011) Reward and punishment effects on error processing and conflict control. Front Psychol 2:335. Medline

Subramaniam K, Kounios J, Parrish TB, Jung-Beeman M (2009) A brain mechanism for facilitation of insight by positive affect. J Cogn Neurosci 21:415-432. CrossRef Medline

van Steenbergen H, Band GP, Hommel B (2009) Reward counteracts conflict adaptation: evidence for a role of affect in executive control. Psychol Sci 20:1473-1477. CrossRef Medline

van Steenbergen H, Band GP, Hommel B (2012) Reward valence modulates conflict-driven attentional adaptation: electrophysiological evidence. Biol Psychol 90:234-241. CrossRef Medline

Verguts T, Notebaert W (2009) Adaptation by binding: a learning account of cognitive control. Trends Cogn Sci 13:252-257. CrossRef Medline

Vertes RP (2006) Interactions among the medial prefrontal cortex, hippocampus and midline thalamus in emotional and cognitive processing in the rat. Neuroscience 142:1-20. CrossRef Medline

Waltz JA, Kasanova Z, Ross TJ, Salmeron BJ, McMahon RP, Gold JM, Stein EA (2013) The roles of reward, default, and executive control networks in set-shifting impairments in schizophrenia. PLoS One 8:e57257. CrossRef Medline

Watson D, Clark LA, Tellegen A (1988) Development and validation of brief measures of positive and negative affect: the PANAS scales. J Pers Soc Psychol 54:1063-1070. CrossRef Medline 